\title{
Synthesis of L-Lactic Acid from Fermentation of Cassava Pulp by Using Tempeh Inoculum
}

\author{
R. C. Nissa1,2,", D. Sumiarsa², W. Kosasih¹, B. Firdiana ${ }^{1}$ and A. H. D. Abdullah¹ \\ ${ }^{1}$ Research Unit for Clean Technology, National Research and Innovation Agency Republic of Indonesia, Bandung 40135, Indonesia \\ 2 Faculty of Biotechnology Padjadjaran University, Bandung 40132, Indonesia
}

\begin{abstract}
This study used cassava waste pulp as a fermentation substrate to produce lactic acid using a tempeh inoculum. Tempeh inoculum is a mixed culture of Rhizopus with Rhizopus oligosporus as the primary fungus. Lactic acid is an organic acid most widely used in the food, pharmaceutical, cosmetic and chemical industries. One of the important uses of lactic acid is as a raw material for producing Polylactic Acid (PLA) biopolymers, namely polymers that can decompose naturally in a relatively fast time. The analysis was performed using the Response Surface Methodology (RSM) method and the Box Behnken Design (BBD) experimental design with substrate concentration parameters, inoculum concentration, and incubation time on lactic acid. The fermentation process is carried out using a flask shaker at a temperature of $30^{\circ} \mathrm{C}, \mathrm{pH} 6.0$, and a rotational speed of $150 \mathrm{rpm}$. The optimum yield for lactic acid is $6.65 \mathrm{~g} / \mathrm{L}$. It was acquired at substrate $20 \mathrm{~g} / \mathrm{L}$, inoculum concentration $0.30 \%$ (w/v) at an incubation time of 72 hours.
\end{abstract}

ARTICLE HISTORY

Received: 6 May 2021

Revised: 4 October 2021

Accepted: 11 October 2021

KEYWORDS

Cassava waste pulp

Lactic acid

Tempeh inoculum

R.S.M. Box-Behnken

\section{INTRODUCTION}

Lactic Acid (LA) has a wide range of applications, especially as a raw material of bio-polymer production [1]. Synthesize of LA from starch-biomass or agricultural residues was begun since this material is cheap and abundant. One of the important LA derivatives (biopolymer Polylactic Acid, PLA) has profound properties; thus, it has been widely used in various applications [2]. PLA is a biodegradable and thermoplastic made by polymerization of LA. PLA is a promising material to overcome global pollution caused by conventional plastic [3].

In producing LA, the utilization of waste by biological processes such as fermentation has an important role [1]. Cassava waste pulp is a potential raw material in LA production. Cassava waste pulp is a solid waste of cassava starch production. The main components are carbohydrates $( \pm 60-65 \%)$, and the remaining $40 \%$ contain moisture, minerals, and crude fiber. Meanwhile, cassava waste pulp is generally used only as fertilizer and animal feed, so it has not been optimally utilized [4, 5]. Several studies on cassava waste pulp utilization as substrate fermentation have started performed [6, 7]. This work chooses cassava waste pulp as a substrate due to its relatively cheap role in overcoming environmental pollution problems.

LA is usually produced by chemical synthesis from petrochemical sources or obtained by microbial fermentation. The LA produced by bacteria fermentation requires complex media, producing an LA racemic mixture [8]. However, fermentation is possibly carried out by using inoculum, such as tempeh-inoculum. The fungi usually cultivated in the inoculum such as $R$. oligosporus, $R$. oryzae, $R$. stolonifer, and $R$. arrhizus [9].

Some works reported that R.oryzae and R.oligosporus could utilize various agricultural residues such as L-LA, fumaric acid, and ethanol to produce LA $[10,11]$. The use of Rhizopus has several advantages; it can suppress downstream processes because of the ease of separating mould filaments. Previous researchers have studied LA fermentation using strain Rhizopus sp, with different carbon sources, nitrogen sources, and operating conditions ( $\mathrm{pH}$, temperature, volume, and rotation speed) but mostly using acid hydrolysis to convert polysaccharides into monosaccharides [10-12]. Acid hydrolysis has drawbacks such as corrosion-resistant tools, carbohydrate degradation and product recombination [8].

Rhizopus sp has the shortest log phase, where the production is the highest mycelium mass occurs from 48 to 96 hours of incubation. After this time, the amount of mycelium remains even much lower than the log phase [13]. Some literature shows that the optimum result for fermentation using Rhizopus is at 72 hours, so that the observation of incubation time is chosen between 0-72 hours [14].

Several researchers have used this technique to optimize the yield of several parameters. This study used RSM-BBD with a factorial arrangement of three levels of fractions that can predict the best optimal value of the LA yield. This methodology could be employed to optimize media for LA fermentation $[10,15]$. This method is to determine the effect of the independent variable on the response, obtain the model of the relationship between the independent variable and the response, and get the optimum condition process. In addition, the advantages of the RSM-BBD method does not require large number of experimental data and efficient time.

This study aims to ferment cassava-waste pulp into LA. The fermentation starter using tempeh inoculum, which has not been widely used in the fermentation process to produce LA. 


\section{EXPERIMENTAL METHOD}

The research was conducted in the bioprocess laboratory Research Unit for Clean Technology, National Research and Innovation Agency Republic of Indonesia (BRIN).

\section{Materials and Instruments}

Dried cassava waste pulp was obtained from Surya Pati Kencana Factories (Pati, Indonesia), sieved 80 mesh. The commercial tempeh inoculum of the Raprima brand, produced by PT Aneka Fermentasi Indonesia (AFI.) Bandung Indonesia. Yeast extract, peptone, $\mathrm{K}_{2} \mathrm{HPO}_{4}, \mathrm{KH}_{2} \mathrm{PO}_{4}, \mathrm{MgSO}_{4} .7 \mathrm{H}_{2} \mathrm{O},\left(\mathrm{NH}_{4}\right)_{2} \mathrm{SO}_{4}, \mathrm{CaCO}_{3}$, Potato Dextrose Agar (PDA) were purchased from Merck (Darmstadt, Germany).

\section{Method and Procedure}

\section{Fermentation Process}

The fermentations at shake flask level $(50 \mathrm{~mL}$ in a $250 \mathrm{~mL}$ Erlenmeyer flask) were carried out using the media described by Kumar et al. [14]. Media fermentation was sterilized using an autoclave (Hirayama H.V.E. 50) at a temperature of $121{ }^{\circ} \mathrm{C}$ for 15 minutes. Fermentation was carried out in a shaker incubator (Jeiotech SI-900R) at a temperature of $30^{\circ} \mathrm{C}$ with a rotating speed of $150 \mathrm{rpm}$ and $\mathrm{pH} 6.0$.

\section{Statistical Optimization}

A three factorial experimental design using the RSM-BBD was applied to optimize the fermentation process using MINITAB 19.1 software. The Design of Experiment (DOE) was formed based on the RSM in doing optimization. The independent variable used is the substrate concentration (A), inoculum concentration (B), and incubation time (C). The response of independent variables will affect LA levels. In this study, the determination of the parameters used are shown in Table 1.

Table 1. The experimental design levels of selected variables

\begin{tabular}{clrr}
\hline Factor & Parameter & Min & \multicolumn{1}{c}{ Max } \\
\hline A & C (g/L) & 20 & 60 \\
B & Inoc $(\% \mathrm{w} / \mathrm{v})$ & 0.10 & 0.30 \\
C & $\mathrm{t}(\mathrm{h})$ & 0 & 72 \\
\hline
\end{tabular}

A :substrate concentration; B: inoculum concentration; and C: incubation time

A second-order polynomial model which includes all interaction terms was defined to fit the response, shown in Equation 1.

$$
Y=\beta_{o}+\sum \beta_{i} X_{i}+\sum \beta_{i i} X_{i 2}+\sum \beta_{i j} X_{i} X_{j}
$$

$\mathrm{Y}$ is the predicted response (LA, $\mathrm{g} / \mathrm{L}$ ), $\beta$ o is the interception coefficient, $\beta \mathrm{i}$ is the linear term, $\beta$ ii is the quadratic term, and $\beta i j$ is the interaction term. Calculation of the predicted responses, analysis of experimental design data, and the plotting of contour and surface plots were made using MINITAB 19.1 software.

Statistical analysis of the data: Data analysis where the response variable $(\mathrm{Y})$ obtained was then analyzed by ANOVA. The coefficient of determination $\left(\mathrm{R}^{2}\right)$ was used to assess the fitting of second-order regression equations. By using three levels of BBD, it will produce 15 experiments.

\section{Characterization}

Cassava waste pulp was tested for proximate characteristics such as moisture, starch, ash, and crude fiber for preliminary testing. Dried cassava waste pulp containing moisture of $11.74 \%$, starch content $59.40 \%$, ash content $1.95 \%$, and crude fiber content $16.42 \%$. The tempeh inoculum was identified and tested for amylase enzyme activity using the Fuwa method [16]. Macroscopic observations were made of fungal colonies' color growth on the petri dish. Microscopic observations were analyzed using microscope Fluorosence Meiji Techno MT 6300 to know Rhizopus type in the tempeh inoculums [9]. Response testing LA production; The supernatant was measured with a Conductometer to determine its electrical conductivity, then plotted on the standard curve LA [17]. A regression equation is obtained from the standard curve of the conductivity measurement to calculate the yield of LA production $(\mathrm{g} / \mathrm{L})$. The equation leads to regression formula in Equation 2.

$$
y=a \cdot x+b
$$

$\mathrm{y}$ is electrical conductivity $(\mathrm{mS} / \mathrm{cm})$, a is the slope, $\mathrm{b}$ is the $\mathrm{y}$-intercept, and $\mathrm{x}$ is the yield of LA production $(\mathrm{g} / \mathrm{L})$.

FT-IR spectroscopy (Thermo Scientific Nicolet iS5, Madison, U.S.A.) identifies the functional groups resulting from LA fermentation[18]. 


\section{RESULT AND DISCUSSION}

Based on macroscopic and microscopic at 100x magnification, which was then compared with the standard, the type (a) resembled $R$. oligosporus, and (b) reached as $R$. oryzae. The results of the isolation of pure culture from the tempeh inoculum are shown in Figure 1. This study's results indicated insulation on fungal isolates color tempeh inoculum greyish black and greyish-white in 48 hours of incubation. After more than 72 hours, the colony starts to turn grey-brown and greyish black.
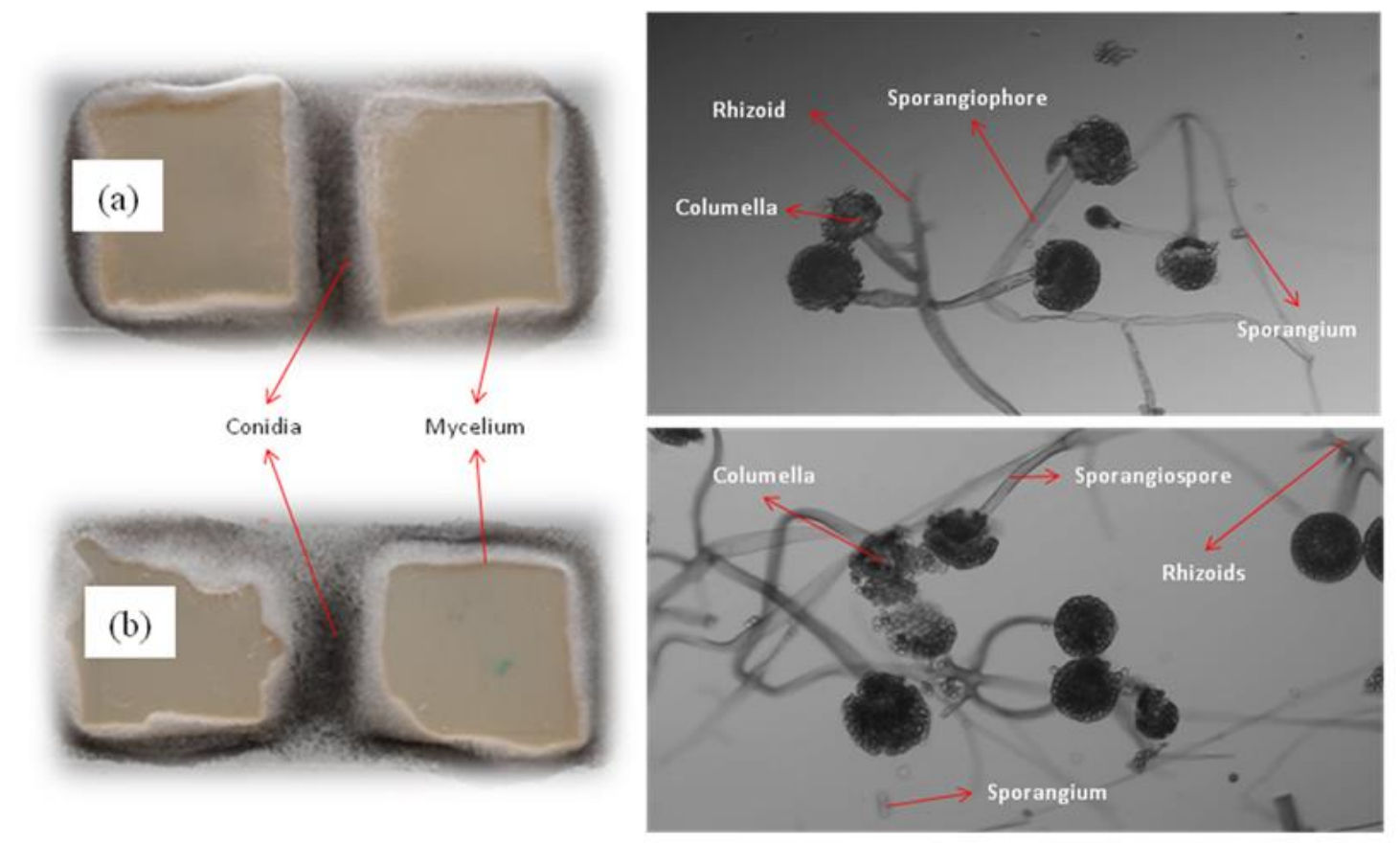

Figure 1. Macroscopic (left) and microscopic (right) morphology 100x magnification of (a) R. Oligosporus and (b) R.oryzae syn R.arrhizus in Potato Dextrose Agar after seven days incubation using Microscope Fluorescence

R.oligosporus has a shorter sporangiospores length than R.oryzae, which has short rhizoids. In seven days, the sporangium rupture causes the spores to leak out of the columella. In comparison, R.oryzae has a diameter of sporangium and columella larger than R.oligosporus. For R. Oryzae, sporangiospores were unequal, numerous, irregular, sub-globose or oval, angular with striations, $6 \sim 10 \mu \mathrm{m}$ in length. Sporangiophores were usually straight, smooth-walled, simple or branched, non-septate, long, and arose from stolons opposite rhizoids, usually in $3 \sim 5 \mu \mathrm{m}$ or more. Sporangia were globose, white at first, and then turned black with many spores. Columella was globose to sub-globose in shape, pale brown in color, Rhizoids and stolons were dark brown (Figure 1) [19]. R. oligosporus has brownish-gray colonies with a height of $1 \mathrm{~mm}$ or more. A single colony or in a group have smooth or rather rough walls. Sporangia globose is brownishblack. Chlamydospores have single and short, colorless chains containing granules formed on hyphae, sporangiophores, and sporangia [9]. The form of Chlamydospora globose, ellipse, or cylindrical. For morphology, the details are shown in Table 2.

Table 2. Comparison of the morphological characteristics of fungi isolated from Tempeh inoculum commercial with previous features of $R$. oligosporus and R. Oryzae

\begin{tabular}{|c|c|c|c|c|}
\hline \multirow[t]{2}{*}{ Characteristics } & \multicolumn{2}{|c|}{$\begin{array}{l}\text { Identification of the commercial } \\
\text { tempeh inoculum by microscope }\end{array}$} & \multicolumn{2}{|c|}{ Reference } \\
\hline & $\mathbf{A}$ & B & R. oligosporus [20] & R. oryzae [21] \\
\hline Conidia color & $\begin{array}{r}\text { Brownish } \\
\text { grey }\end{array}$ & $\begin{array}{l}\text { Brownish grey } \\
\text { to blackish-grey }\end{array}$ & Brownish-grey & $\begin{array}{l}\text { Brownish grey } \\
\text { to blackish-grey }\end{array}$ \\
\hline Mycelium color & White & White & White & White \\
\hline Sporangiophore Size & $78-121 \mu \mathrm{m}$ & $171-420 \mu \mathrm{m}$ & $150-400 \mu \mathrm{m}$ & $150-1000 \mu \mathrm{m}$ \\
\hline Sporangiospore shape & $\begin{array}{r}\text { Sub-globose to } \\
\text { ellipsoidal }\end{array}$ & $\begin{array}{r}\text { Sub-globose or } \\
\text { oval }\end{array}$ & $\begin{array}{r}\text { Sub-globose to } \\
\text { ellipsoidal }\end{array}$ & Sub-globose or oval \\
\hline Diameter sporangium & $49-76 \mu \mathrm{m}$ & 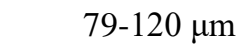 & 80-120 $\mu \mathrm{m}$ & $>150 \mu \mathrm{m}$ \\
\hline Columella length & $28 \mu \mathrm{m}$ & $36 \mu \mathrm{m}$ & $25-27 \mu \mathrm{m}$ & $80-110 \mu \mathrm{m}$ \\
\hline Texture sporangiophore & smooth & smooth & smooth & smooth \\
\hline
\end{tabular}


Columella shape

Conidia diameter
Globose to subglobose $6 \mu \mathrm{m}$
Globose to sub-globose
Globose to

sub-globose
Globose to sub-globose $4-10 \mu \mathrm{m}$

Based on Table 2, comparing the macroscopic and microscopic analysis of the tempeh inoculum with reference states that the commercial tempeh inoculum was assumed to contain $R$. oryzae and $R$. oligosporus fungi type producing amylase and glucoamylase enzymes [22]. It was seen from the similarity of shapes, sizes, and colors based on reference, but there are also differences in morphology of Rhizopus compared to the standard due to the different strains of Rhizopus[19]. The tempeh inoculum's enzyme activity test result was amylase of $79.00 \mathrm{U} / \mathrm{mL}$. Converting polysaccharides into monosaccharides (glucose) enzymatically involves a group of the amylase enzymes, where glucose will be used as a carbon source for the LA fermentation process. According to research by Freitas et al., the amylase enzymes produced from $R$. oryzae and $R$. oligosporus were converted $95 \%$ and $96 \%$ of the starch into glucose in 3.5 hours of reaction. This statement shows us that the commercial tempeh inoculums are the best choice due to converting $95 \%-96 \%$ of polysaccharides into monosaccharides in only 3.5 hours [23].

Figure 2 was LA produced by the fermentation process, which has brownish yellow color because it still contains sugar and nitrogen sources residues. Figure 3 shows the FT-IR spectrum of standard LA, L (+) - lactate, and the results of LA fermentation with calcium carbonate precipitates. FT-IR spectrum of L $(+)$ - fermented calcium lactate has a higher carbonyl bond at $1500 \sim 1750 \mathrm{~cm}^{-1}$ than others.

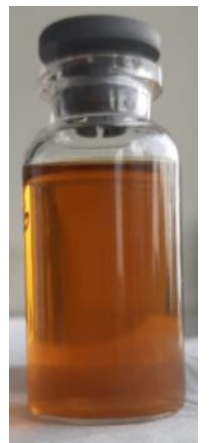

Figure 2. LA Fermentation with Calcium Carbonate Precipitates

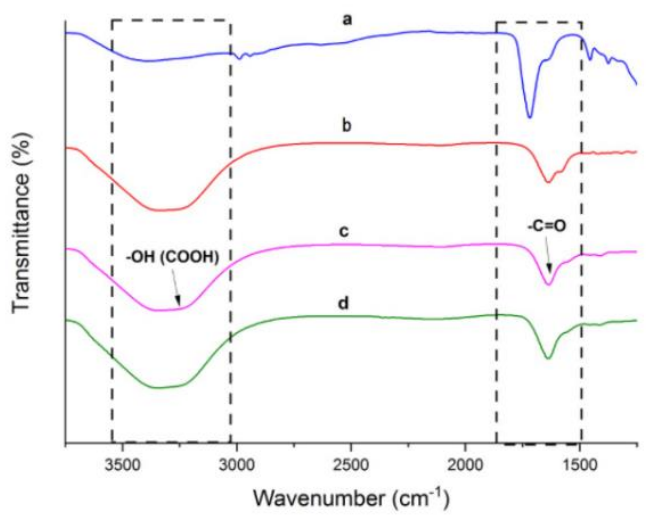

Figure 3. Validation of ( $c$ and d) LA fermentation with calcium carbonate precipitates, compared with

(a) the standard of LA and (b) L(+)-lactate using FT-IR

In the results of LA fermentation, we found that the characteristic signal was around $3000 \sim 3500 \mathrm{~cm}^{-1}(\mathrm{OH}$ band) with a very high density visible in the sample (c and d). Still, the density was not too high at LA standard, possibly due to differences in purity levels. The LA spectrum is interesting because it has two types of O-H; one comes from acids, and the other comes from alcohol. The acidic $\mathrm{OH}$ bonds will be absorbed in the area between 2500 and $3300 \mathrm{~cm}^{-1}$, while the alcohol will absorb between 3230 and $3550 \mathrm{~cm}^{-1}$. When they occur together, they will provide a large absorption area between 2500 and $3550 \mathrm{~cm}^{-1}$. At $1500 \sim 1750 \mathrm{~cm}^{-1}(\mathrm{C}=\mathrm{O}$ stretch$)$, and $1300 \sim 1500 \mathrm{~cm}^{-1}(\mathrm{CH}$ bending), the standard intensity is higher than the fermented sample; because the sample is not yet pure. The spectrum results show that a specific functional group of LA has been formed, as evidenced by peaks at $3000 \sim 3500 \mathrm{~cm}^{-1}$ and $1500 \sim 1750 \mathrm{~cm}^{-1}$ [18]. So it can be concluded, the results of FT-IR analysis of the fermentation sample with calcium carbonate precipitates show that the sample contains L-lactate, but it is not yet pure.

This study investigated the relationship between three independent variables (substrate concentration, inoculum concentration, and incubation time) on LA production. The optimum value of parameters for maximum LA production was determined using statistical BBD. According to the design matrix given in Table 1. Experimental data (Table 3) were 
analyzed using statistical methods following the Design of Experimental. Multiple regression analysis of experimental data yields the following second-order polynomial equation, in Equation 3.

$$
\begin{aligned}
L A\left(\frac{g}{L}\right)=-0.150-0.0261(A)+9.96(B)+0.1377(C)+0.000960(A)^{2}-0.90(B)^{2} \\
-0.000954(C)^{2}-0.2501(A) .(B)-0.000544(A) .(C)+0.0826(B) .(C) .
\end{aligned}
$$

From Equation 3, the curve fitting for LA production can be calculated which the data can be compared with the experimental value (Table 3). If the value between the curve fitting and the experimental results is too far away, other factors may affect LA production. The experiment result was obtained from the measurement of electrical conductivity. Afterwards, a regression equation is obtained to calculate the yield of LA production $(\mathrm{g} / \mathrm{L})$ from the standard curve of the conductivity measurement. Equation 4 is the equation from the standard curve of conductivity measurement:

$$
y=3,2133 \cdot x+5,5392
$$

Table 3. BBD the design of experimentally used in RSM studies by using three variables showing observed LA production

\begin{tabular}{ccccccc}
\hline \multirow{2}{*}{$\begin{array}{c}\text { Run } \\
\text { orders }\end{array}$} & $\begin{array}{c}\mathrm{A} \\
(\mathrm{g} / \mathrm{L})\end{array}$ & $\begin{array}{c}\mathrm{B} \\
(\% \mathrm{w} / \mathrm{v})\end{array}$ & $\begin{array}{c}\mathrm{C} \\
(\mathrm{h})\end{array}$ & $\begin{array}{c}\text { Conductivity } \\
\mathrm{mS} / \mathrm{cm}\end{array}$ & $\begin{array}{c}\text { LA production }(\mathrm{g} / \mathrm{L}) \\
\text { Fitting }\end{array}$ & Experimental \\
\hline 1 & 60 & 0.20 & 0 & 7.12 & 0.69 & 0.49 \\
2 & 40 & 0.10 & 72 & 19.14 & 5.11 & 4.23 \\
3 & 40 & 0.10 & 0 & 7.19 & 0.33 & 0.51 \\
4 & 40 & 0.30 & 0 & 6.63 & 0.25 & 0.34 \\
5 & 40 & 0.20 & 36 & 17.43 & 3.83 & 3.70 \\
6 & 60 & 0.30 & 36 & 17.40 & 3.58 & 3.69 \\
7 & 40 & 0.30 & 72 & 22.40 & 4.65 & 5.24 \\
8 & 40 & 0.20 & 36 & 18.17 & 3.83 & 3.93 \\
9 & 20 & 0.20 & 0 & 7.44 & 0.67 & 0.59 \\
10 & 60 & 0.20 & 72 & 20.25 & 5.28 & 4.58 \\
11 & 20 & 0.20 & 72 & 25.60 & 5.26 & 6.24 \\
12 & 20 & 0.30 & 36 & 22.64 & 4.56 & 5.32 \\
13 & 40 & 0.20 & 36 & 17.93 & 3.83 & 3.85 \\
14 & 60 & 0.10 & 36 & 18.67 & 4.85 & 4.09 \\
15 & 20 & 0.10 & 36 & 17.48 & 3.83 & 3.72 \\
\hline
\end{tabular}

A : concentration of cassava waste

B : concentration of tempeh inoculums

C : incubation time

\begin{tabular}{|c|c|c|c|c|c|}
\hline Source & Degree of Freedom & Adj SS. & $\begin{array}{r}\text { Adj Mean } \\
\text { square }\end{array}$ & F-Value & P-Value \\
\hline Model & 9 & 52.3024 & 5.8114 & 125.89 & 0.000 \\
\hline Error & 5 & 0.2308 & 0.0462 & & \\
\hline Pure Error & 2 & 0.0276 & 0.0138 & & \\
\hline Total & 14 & 52.5332 & & & \\
\hline $\mathrm{R}^{2}$ & $=$ & 0.9956 & & & \\
\hline Adj $R^{2}$ & $=$ & 0.9877 & & & \\
\hline $\mathrm{R}^{2}$ (prediction) & $=$ & 0.9369 & & & \\
\hline Lack of Fit & 3 & 0.2032 & 0.0677 & 4.91 & 0.174 \\
\hline
\end{tabular}

LA: Yield of LA

Table 4. ANOVA for response surface of LA production

Based on the prediction RSM to optimization of LA production $(\mathrm{g} / \mathrm{L})$ by tempeh inoculum was $\mathrm{A}=20 \mathrm{~g} / \mathrm{L}, \mathrm{B}=0.30$ $\%(\mathrm{w} / \mathrm{v})$, and $\mathrm{C}=72$ hours, will produce $\mathrm{LA}=7.08 \mathrm{~g} / \mathrm{L}$. Three repetitions were carried out to confirm optimum conditions, and an average value of $6.65 \mathrm{~g} / \mathrm{L}$ was obtained. This value is very close to the predicted optimum value, $7.08 \mathrm{~g} / \mathrm{L}$. The experiment validated the optimum conditions predicted by the BBD. The percentage of error between the experimental 
results and the curve fitting is $0.38 \%$. The $\mathrm{R}^{2}$ value (0.9956) indicates that the sample variation for LA of $99.56 \%$ was attributed to the independent variables, and the model cannot explain only $0.44 \%$ of the total variation.

The adjusted determination coefficient $\left(\operatorname{adj} . \mathrm{R}^{2}=0.9877\right)$ was also satisfactory for confirming the model's significance. The closer to number one, the higher the value of optimization accuracy. The analysis results also showed a significant interaction between cassava waste pulp substrate and the inoculum content. The relationships between independent variables can be better understood by examining the series's response surface and contour plots. Figures 4 to 6 represent surface plots and contour plots for optimizing LA fermentation conditions. The response surface's primary objective is to efficiently determine the variable's optimal value to maximize or minimize response. The smallest ellipse in the contour diagram is the maximum predicted value indicated by the boundary surface. Less substrate causes microorganisms to lack substrate in their reproduction; Conversely, more substrate concentration causes microorganisms to experience a long phase delay (adaptation). The interaction between the substrate concentration and the inoculum concentration can be seen in Figure 4.
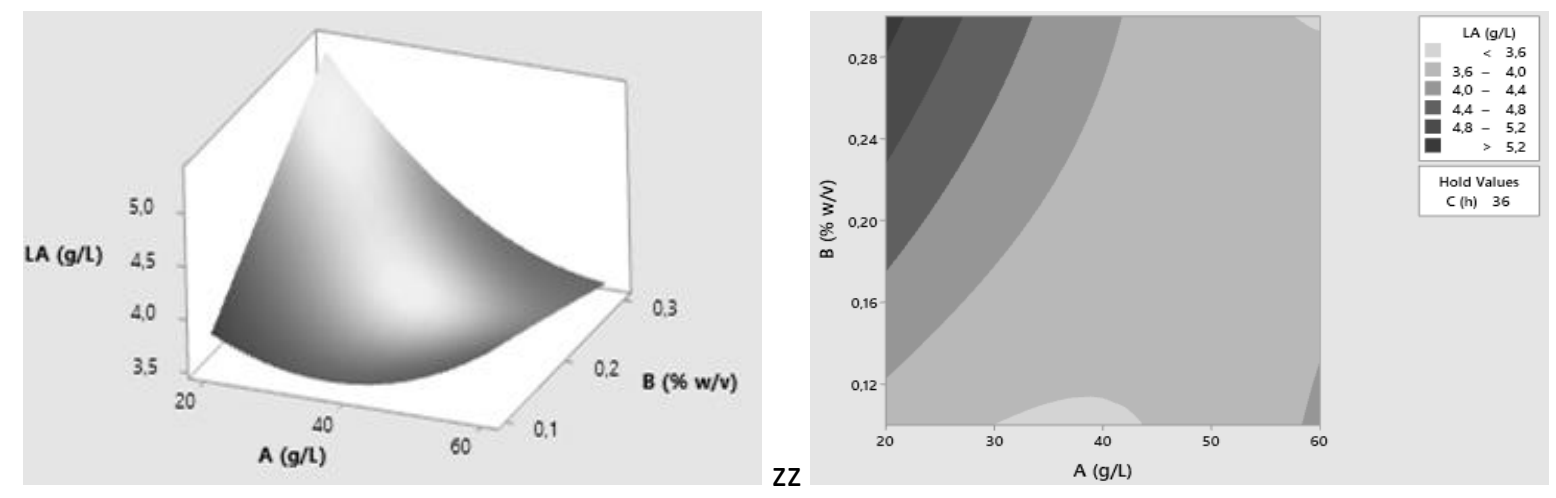

Figure 4. Response surface plot and contour plot showing the effect of substrate concentration, inoculum concentration, and their mutual impact on LA production $(\mathrm{g} / \mathrm{L})$.
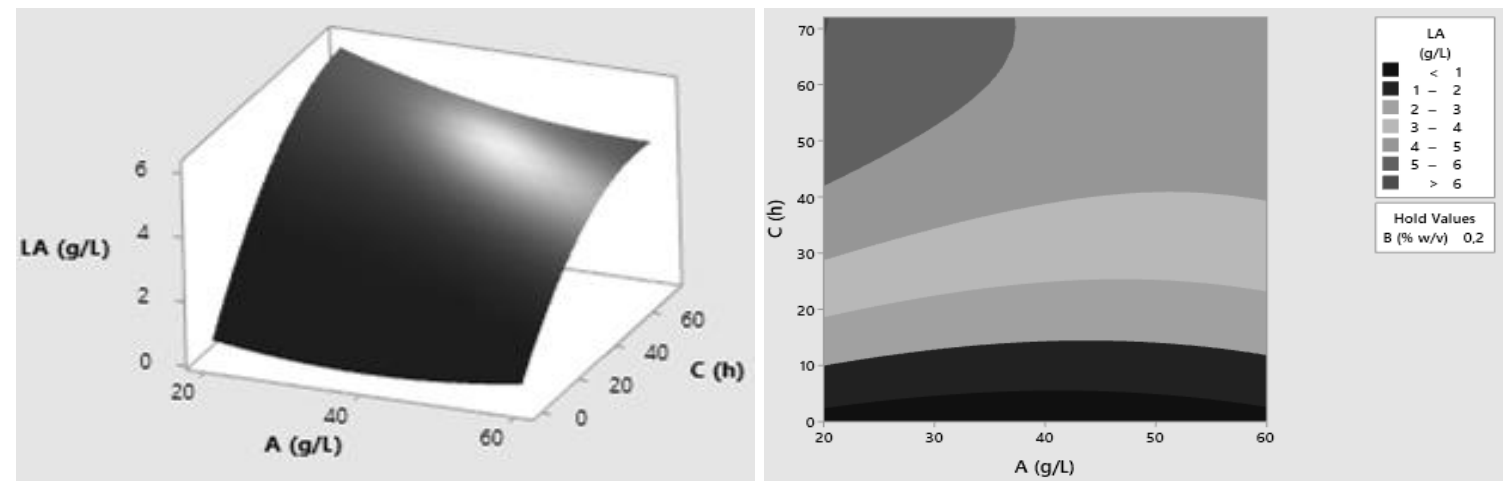

Figure 5. Response surface plot and contour plot showing the effect of substrate concentration, incubation time, and their mutual impact on LA production $(\mathrm{g} / \mathrm{L})$.
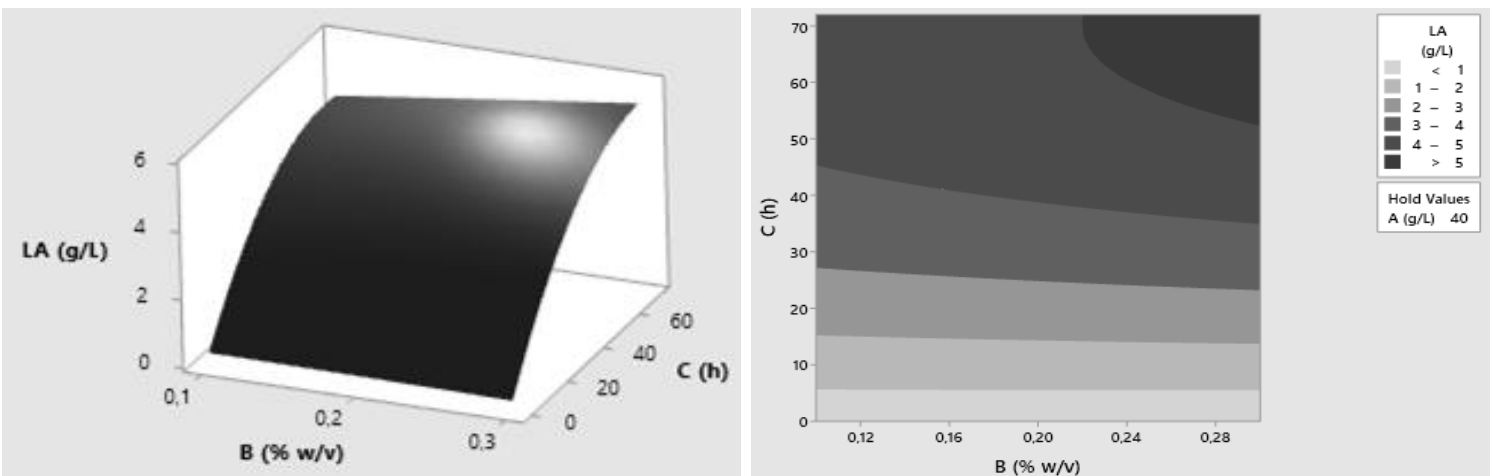

Figure 6. Response surface plot and contour plot showing the effect of inoculum concentration, incubation time, and their mutual impact on LA production $(\mathrm{g} / \mathrm{L})$. 


\section{CONCLUSION}

Commercial tempeh inoculums and cassava waste pulp as LA producers makes the effective fermentation process for bioplastic technology. The optimum condition at a cassava waste pulp concentration of $20 \mathrm{~g} / \mathrm{L}$ and $0.30 \%(w / v)$ tempeh inoculum with 72 hours of incubation time yields a maximum LA production of $6.65 \mathrm{~g} / \mathrm{L}$. However, a well-established study on microorganisms producing LA with renewable raw material using the RSM technique still requires more research to be generalized and applied to a broader LA industry scope.

\section{ACKNOWLEDGEMENT}

The author is very thankful to Research Unit for Clean Technology, National Research and Innovation Agency Republic of Indonesia and Biotechnology Master Program, Faculty of Postgraduate, Padjadjaran University, for providing the necessary facilities for this work.

\section{REFERENCES}

[1] M. A. Abdel-Rahman et al., "One-factor-at-a-time and response surface statistical designs for improved lactic acid production from beet molasses by Enterococcus hirae ds10,” SN Appl. Sci., vol. 2, no. 4, pp. 1-14, 2020.

[2] T. Casalini, F. Rossi, A. Castrovinci, and G. Perale, "A Perspective on Polylactic Acid-Based Polymers Use for Nanoparticles Synthesis and Applications," Front. Bioeng. Biotechnol., vol. 7, no. October, pp. 1-16, 2019.

[3] G. Li et al., "Synthesis and Biological Application of Polylactic Acid," Molecules, vol. 25, no. 21, p. 5023, Oct. 2020.

[4] P. Febriyanto and A. W. Satria, "Kajian Awal Pemanfaatan Limbah Onggok Sebagai Substitusi Batubara,” vol. 8, no. 1, pp. 14-18, 2019.

[5] Sutikno, Marniza, Selviana, and N. Musita, "Pengaruh konsetrasi enzim selulase, $\alpha$-amilase dan glukoamilase terhadap kadar gula reduksi dari onggok," J. Teknol. Ind. dan Hasill Pertan., vol. 21, no. 1, pp. 1-12, 2016.

[6] H. Chen et al., "Efficient lactic acid production from cassava bagasse by mixed culture of Bacillus coagulans and lactobacillus rhamnosus using stepwise $\mathrm{pH}$ controlled simultaneous saccharification and co-fermentation," Ind. Crops Prod., vol. 146, no. 15, p. 112175, 2020.

[7] J. V. Carpinelli Macedo, F. F. de Barros Ranke, B. Escaramboni, T. S. Campioni, E. G. Fernández Núñez, and P. de Oliva Neto, "Cost-effective lactic acid production by fermentation of agro-industrial residues," Biocatal. Agric. Biotechnol., vol. 27, no. July, p. 101706, 2020.

[8] J. Romo-Buchelly, M. Rodríguez-Torres, and F. Orozco-Sánchez, "Biotechnological valorization of agro industrial and household wastes for lactic acid production," Rev. Colomb. Biotecnol., vol. 21, no. 1, pp. 113-127, 2019.

[9] Y. Sine and E. S. Soetarto, "Isolasi dan identifikasi kapang Rhizopus pada tempe gude (Cajanus cajan L.)," Savana Cendana, vol. 3, no. 04, pp. 67-68, 2018.

[10] Y. Q. Fu, L. F. Yin, H. Y. Zhu, and R. Jiang, "High-efficiency L-lactic acid production by Rhizopus oryzae using a novel modified one-step fermentation strategy," Bioresour. Technol., vol. 218, pp. 410-417, 2016.

[11] A. S. Azmi, N. Yusuf, D. N. Jimat, and N. I. M. Puad, "Co-production of lactic acid and ethanol using rhizopus sp. from hydrolyzed inedible cassava starch and leaves," IIUM Eng. J., vol. 17, no. 2, pp. 1-10, 2016.

[12] T. Yuwa-amornpitak and K. Chookietwatana, "Bioconversion of waste cooking oil glycerol from cabbage extract to lactic acid by Rhizopus microsporus," Brazilian J. Microbiol., vol. 49, pp. 178-184, 2018.

[13] D. Junaidi, M. C. K. P. Santoso, E. S. Retnoningtyas, and S. B. Hartono, "Penurunan kadar sianida pada umbi gadung (Dioscorea hispida) dengan proses fermentasi menggunakan kapang Rhizopus Oryzae," Widya Tek., vol. 14, no. 1, pp. 9-14, 2018.

[14] R. Kumar and S. Shivakumar, "Production of L-Lactic acid from starch and food waste by amylolytic Rhizopus oryzae MTCC 8784,” Int. J. ChemTech Res., vol. 6, no. 1, pp. 527-537, 2014.

[15] V. Sridevi, M. Padmaja, A. Sahitya, N. Vardhan, and G. Rao, "Application of Box-Behnken Design for the Optimized Production of Lactic Acid by Newly Isolated Lactobacillus plantarum JX183220 Using Cassava (Manihot esculenta Crantz) Flour,” Br. Biotechnol. J., vol. 9, no. 2, pp. 1-9, 2015.

[16] R. C. Orlandelli, M. S. Santos, J. C. Polonio, J. L. de Azevedo, and J. A. Pamphile, "Use of agro-industrial wastes as substrates for $\alpha$-amylase production by endophytic fungi isolated from Piper hispidum Sw," Acta Sci. - Technol., vol. 39, no. 3, pp. 255-261, 2017.

[17] T. Payot and M. Fick, "On-line estimation of lactic acid concentration by conductivity measurement in fermentation broth,” Biotechnol. Tech., vol. 11, no. 1, pp. 17-20, 1997.

[18] S. H. Cheong, "Physicochemical properties of calcium lactate prepared by single-phase aragonite precipitated calcium carbonate," Res. J. Pharm. Biol. Chem. Sci., vol. 7, no. 1, pp. 1786-1794, 2016.

[19] Y. Vebliza, W. Sjamsuridzal, A. Oetari, I. Santoso, and I. G. Roosheroe, "Re-identification of five strains of Rhizopus arrhizus from tempeh based on ITS regions of rDNA sequence data," AIP Conf. Proc., vol. 2023 , no. October, 2018.

[20] A. S. Duniaji, W. Wisaniyasa, N. N. Puspawati, and dan N. M. Indri H, "Isolation and Identification of Rhizopus 
oligosporus Local Isolate Derived from Several Inoculum Sources,” Int. J. Curr. Microbiol. Appl. Sci., vol. 8, no. 09, pp. 1085-1098, 2019.

[21] R. Y. Zheng, G. Q. Chen, H. Huang, and X. Y. Liu, “A monograph of Rhizopus,” Sydowia, vol. 59, no. 2, pp. 273$372,2007$.

[22] H. Kaur, "Optimization of $\alpha$-amylase and glucoamylase production in solid state fermentation of deoiled rice bran (DRB) by Rhizopus oryzae," Int. J. Pure Appl. Biosci., vol. 3, no. 6, pp. 249-256, 2015.

[23] A. C. De Freitas, B. Escaramboni, A. F. A. Carvalho, V. M. G. De Lima, and P. De Oliva-Neto, "Production and application of amylases of Rhizopus oryzae and Rhizopus microsporus var. oligosporus from industrial waste in acquisition of glucose," Chem. Pap., vol. 68, no. 4, pp. 442-450, 2014. 